\title{
BMJ Open Trajectories of disposable income among people of working ages diagnosed with multiple sclerosis: a nationwide register-based cohort study in Sweden 7 years before to 4 years after diagnosis with a population-based reference group
}

\author{
Chantelle Murley, ${ }^{1}$ Olof Mogard, ${ }^{1}$ Michael Wiberg, ${ }^{1}$ Kristina Alexanderson, \\ Korinna Karampampa, ${ }^{1}$ Emilie Friberg, ${ }^{1}$ Petter Tinghög ${ }^{1,2}$
}

To cite: Murley C, Mogard 0, Wiberg M, et al. Trajectories of disposable income among people of working ages diagnosed with multiple sclerosis: a nationwide register-based cohort study in Sweden 7 years before to 4 years after diagnosis with a population-based reference group. BMJ Open 2018;8:e020392. doi:10.1136/ bmjopen-2017-020392

- Prepublication history for this paper is available online. To view these files, please visit the journal online (http://dx.doi. org/10.1136/bmjopen-2017020392).

Received 3 November 2017 Revised 14 March 2018 Accepted 5 April 2018

D) Check for updates

${ }^{1}$ Division of Insurance Medicine, Department of Clinical Neuroscience, Karolinska Institutet, SE-171 77 Stockholm, Sweden

${ }^{2}$ Department of Health Sciences, Swedish Red Cross University College, 14121 Huddinge, Sweden

Correspondence to Chantelle Murley; chantelle.murley@ki.se

\section{ABSTRACT}

Objectives To describe how disposable income (DI) and three main components changed, and analyse whether DI development differed from working-aged people with multiple sclerosis (MS) to a reference group from 7 years before to 4 years after diagnosis in Sweden.

Design Population-based cohort study, 12-year follow-up (7 years before to 4 years after diagnosis).

Setting Swedish working-age population with microdata linked from two nationwide registers.

Participants Residents diagnosed with MS in 2009 aged $25-59$ years $(n=785)$, and references without MS $(\mathrm{n}=7847)$ randomly selected with stratified matching (sex, age, education and country of birth).

Primary and secondary outcome measures DI was defined as the annual after tax sum of incomes (earnings and benefits) to measure individual economic welfare. Three main components of DI were analysed as annual sums: earnings, sickness absence benefits and disability pension benefits.

Results We found no differences in mean annual DI between people with and without MS by independent t-tests ( $p$ values between 0.15 and 0.96 ). Differences were found for all studied components of DI from diagnosis year by independent t-tests, for example, in the final study year (2013): earnings (-64 867 Swedish Krona (SEK); 95\% Cl-79 203 to -50 528); sickness absence benefits (13 330 SEK; $95 \% \mathrm{Cl} 10042$ to 16500 ); and disability pension benefits ( 21360 SEK; $95 \% \mathrm{Cl} 17380$ to 25350 ). A generalised estimating equation evaluated DI trajectory development between people with and without MS to find both trajectories developed in parallel, both before $(-4039$ SEK; $95 \% \mathrm{Cl}-10536$ to 2458$)$ and after (-781 SEK; $95 \% \mathrm{Cl}-6988$ to 5360 ) diagnosis.

Conclusions The key finding of parallel DI trajectory development between working-aged MS and references suggests minimal economic impact within the first 4 years of diagnosis. The Swedish welfare system was responsive to the observed reductions in earnings around
Strengths and limitations of this study

- The main strengths of this study include both the population-based design and use of nationwide registers with high completeness and validity, which enabled measurement of multiple sources of income of a recently diagnosed multiple sclerosis (MS) cohort.

- The longitudinal study design with repeated measures enabled the study of the development of disposable income for working-aged people with MS prediagnosis and postdiagnosis, in addition to the difference in annual levels of different income sources to a population-based reference group.

- While residual confounding cannot be excluded, the reference group was a randomised stratified matched group from the general population at a ratio of 1:10.

- An important limitation is that this study does not address the long-term association between economic welfare and MS, as the follow-up was only 4 years in the postdiagnosis period.

MS diagnosis through balancing DI with morbidity-related benefits. Future decreases in economic welfare may be experienced as the disease progresses, although thorough investigation with future studies of modern cohorts are required.

\section{INTRODUCTION}

Multiple sclerosis (MS) is the leading cause of non-traumatic neurological disability in younger adults. ${ }^{1-4}$ People with MS (PwMS) in Sweden have a mean onset age of 33 years for first symptoms, but experience a time-lag of 6-7 years before receiving a formal diagnosis with this chronic and progressive disease. ${ }^{5}$ 
Previous research has found MS to be associated with progressive work incapacity, due to physical disability worsening as time from onset increases. ${ }^{5-11}$ Therefore, levels of absenteeism, with high proportions working part time and exiting paid work, and presenteeism, with reduced work productivity, increase over the disease course. ${ }^{59}$ However, there is uncertainty and variability among PwMS in progression to disability milestones. ${ }^{12}$ The indirect costs of working-aged PwMS become a dominating cost as the disease progresses from a societal perspective. ${ }^{513-15}$ Nonetheless, the impact of MS on the individual's economic welfare remains relatively unknown.

Earnings remain an important income source for PwMS. ${ }^{316}$ However, earnings alone provide an incomplete picture of an individual's economic welfare, limited to describing the individual's labour market participation and income generation. ${ }^{316}$ A recent Swedish survey found that $77 \%$ of PwMS worked part time, and participation in paid work rapidly decreased with advancing disease. ${ }^{5}$

The wider socioeconomic context can mediate the economic impact of MS on the individual. ${ }^{1718}$ The Swedish welfare state aims to protect individuals with chronic disease from economic pressure through universal healthcare and social insurance benefits. The most substantial of these benefits for PwMS are the temporary sickness absence (SA) and permanent or long-term disability pension (DP) benefits; both designed to compensate a proportion of previous earnings reduced by morbidity-related absence.

There is a growing body of evidence of the positive associations between MS progression in terms of physical disability and cognitive function with the morbidity-related benefits. ${ }^{19-22}$ Furthermore, a substantially higher proportion of PwMS receive SA and DP, in comparison with the general population. ${ }^{32123}$ These changes in sources of income are observed to often occur within a few years of symptom onset, indicating that morbidity-related benefits are necessary to consider when investigating the economic situation of working-aged PwMS. ${ }^{16}{ }^{24-26}$ However, the collective impact of these changes in incomes to the individual's economic welfare is largely unknown. Thorough investigation on how MS affects the economic resources available to PwMS in Sweden necessitates the need to longitudinally assess multiple sources of income in totality. $3212327-30$

Disposable income (DI) is composed of multiple income sources, enabling a comprehensive nuanced description of economic welfare that better reflects an individual's consumption potential than the individual income sources. ${ }^{3} 31$ DI is the "sum of factor income (income from work and capital) and net income from transfers (government benefits), minus income taxes, and fees paid to the government'. ${ }^{16}$ Despite an increasing number of studies on PwMS receiving SA and DP benefits or about earnings, little is known about how MS impacts one's DI trajectory development in a welfare state. ${ }^{32021}$ Longitudinal Danish studies have applied DI concepts by combining both earnings before tax and DP benefits, but not income from SA benefits, to suggest PwMS maintain similar trajectories while remaining in paid work. ${ }^{25} 32$ Nevertheless, the full magnitude of the current economic consequences for individuals with MS remains unknown in the Swedish welfare state where the context for MS has changed substantially in recent years due to treatments delaying disability progression and policy environments for SA and DP grants. ${ }^{33-35}$

This study aimed to describe the development of DI and three main components (SA, DP and earnings) among working-aged people diagnosed with MS in the years immediately before and after diagnosis and compare with people without MS, in order to gain knowledge on the economic welfare of working-aged people diagnosed with MS in a welfare state.

\section{METHODS}

\section{Study design}

We conducted a cohort study to measure the levels and development of mean annual DI and its main components (SA, DP and earnings) among PwMS aged 25-59 years at diagnosis in Sweden, in relation to matched references without MS. The index year of diagnosis, 2009, is presented as $\mathrm{Y}_{0}$, with the 7 years of observation before and 4 years after diagnosis as $\mathrm{Y}_{-7}$ to $\mathrm{Y}_{-1}$ and $\mathrm{Y}_{+1}$ to $\mathrm{Y}_{+4}$, respectively.

\section{Data sources}

Person-level data were obtained from the following two nationwide Swedish registers:

1. Longitudinal Integration Database for Health Insurance and Labour Market Studies (LISA), held by Statistics Sweden, was used to obtain sociodemographic variables and the sums of annual income from the different sources across follow-up.

2. National Patient Registers, held by the National Board of Health and Welfare, enabled identification of all people with an MS diagnosis. The registers contain healthcare visits for inpatient treatment by the International Classification of Diseases (ICD) codes, ICD 9th Revision (340) and ICD 10th Revision (ICD10) (G35) (1987-2009), and specialised outpatient treatment by ICD-10 (2001-2009).

The linkage of data was performed using the unique personal identity numbers assigned to every resident in Sweden.

\section{Study population}

The study population was sourced from the total population registered as living in Sweden on 31 December 2009 (from LISA). The cohort of PwMS included all 785 PwMS identified with an incident MS diagnosis in 2009 and on 31 December 2009 aged 25-59 years. The age range allowed for the cohort to be of working ages in all studied years, with 65 years being the customary age for old-age pension in Sweden. All people with their first MS diagnosis according to the National Patient Registers in 2009 were included, excluding all with a previous MS diagnosis 
(according to the inpatient and specialised outpatient registers). ${ }^{23}$

We established a matched reference cohort of people who before 2010, according to the inpatient and specialised outpatient registers, were not diagnosed with MS. Among all without MS who, according to LISA, lived in Sweden 31 December 2009, we randomly selected 10 references for each PwMS, matched on age, gender, educational level and birth country in $2009\left(\mathrm{Y}_{0}\right)$. This produced a stratified matched reference group with the same distribution of the selected sociodemographic variables in $Y_{0}$ to the MS cohort. The 1:10 ratio of references could not be met for one individual with MS, with only seven possible references in the general Swedish population matching the particular combination of sociodemographic variables. In all, 7847 references were included at $Y_{0}$.

The maximum number of years of observation was 12 , with 97.3\% ( $\mathrm{n}=764)$ of the PwMS and 97.8\% (n=7671) of the reference group in the study at the end of follow-up $\left(\mathrm{Y}_{+4}\right)$. Missing income data in LISA, due to migration before/after the index year or death after $\mathrm{Y}_{0}$, led to small proportions of individuals across both groups not being followed for the entirety of follow-up.

\section{Patient and public involvement}

This was a study based on national register data, and there was no patient or public involvement.

\section{Variables}

Our main outcome measure was annual DI. We used the DI measure constructed by Statistics Sweden, contained in LISA. This was the sum of incomes after tax, with sources including: income from work and public benefits such as DP, SA, disability allowance, unemployment compensation, old-age pension and social assistance. ${ }^{36}$ DI was an individualised measure of household DI, calculated as the sum of household incomes, adjusted for household size and the individual's consumption weight to produce a continuous variable. ${ }^{36}$

The three main components of DI for working-aged PwMS were also included as secondary economic outcomes in analyses as the mean annual sum:

- SA: all people living in Sweden above the age of 16 years are covered by public sick-leave insurance if they receive income from work or unemployment benefits and, if due to disease or injury, have work incapacity. The Social Insurance Agency pays the granted SA benefits, of up to $80 \%$ of lost earnings, at $100 \%, 75 \%, 50 \%$ or $25 \%$ of ordinary working hours. Among employees, the employer provides sick pay in the first 13 days of a sick-leave spell after the first uncompensated day.

- DP: all residents aged 19-64 years can be granted DP if disease or injury leads to long-term or permanent work incapacity. Benefits of up to $64 \%$ of the lost earnings are paid by the Social Insurance Agency, at $100 \%, 75 \%, 50 \%$ or $25 \%$ of ordinary working hours.
- Earnings: income from work was in the form of gross earnings (before tax deductions). This included the sick pay provided by the employer during the first 14 days of a sick-leave spell.

Earnings were presented in gross form, and only two potential public benefit payments were included in the analyses; therefore, one cannot sum the three components to the presented DI values. All monetary values were presented in Swedish Krona (SEK) and adjusted for inflation by the Statistics Sweden Harmonised Consumer Price Index (HCPI) by the annual average 2016 value. ${ }^{37}$

The following sociodemographic variables, sourced from LISA, were included in the analyses as explanatory variables:

- Age (continuous, time variant): in addition, age was also computed into a new continuous variable to control for curvilinearity in the statistical analyses by squaring the values for age.

- Gender (binary).

- Educational level (categorical, time variant: elementary; high school; college or university; and missing).

- Birth country (categorical: Sweden, other Nordic countries, other EU25 countries; rest of world and missing).

The study cohort had near complete data with less than $0.25 \%$ missing values for country of birth and $0.5 \%$ for educational level.

\section{Statistical analyses}

Data management and statistical analyses were conducted in SAS V.9.4, with the exception of generalised estimating equation (GEE) models, which were calculated in SPSS V.24.

In our data management, we set 337 negative DI values between 2004 and 2013 to zero to prevent distortion of the DI means over time. This was required as Statistics Sweden changed how they coded DI in LISA; earlier years of follow-up had a lower limit of zero, but negative values were possible from 2004. We trimmed extreme outlier DI values at $566100 \mathrm{SEK}$, representing the 99th percentile of annual DI across all study years. This made the distribution of DI reasonably normal for statistical analyses. Individuals with missing values in LISA for DI and the secondary outcomes, in years other than $Y_{0}$, were excluded in descriptive statistics for the respective years but were included in the GEE model. Earnings were also capped at the 99th percentile (810 $400 \mathrm{SEK}$ ) to control for extreme outliers.

Descriptive statistics were performed to describe the distribution of sociodemographic variables and summarise the levels of the different incomes. Categorical data were expressed as frequency distributions with the number and percentage. Continuous data were reported for both the PwMS and the reference group, expressed by the mean, $95 \% \mathrm{CI}$ and both the number and proportion with annual sums $>0 .^{38}$

The means of annual DI of PwMS was calculated for each year, $\mathrm{Y}_{-7}$ to $\mathrm{Y}_{+4}$. The differences in mean annual DI 
of PwMS were tested for statistical significance by dependent t-tests between the following three time points: $\mathrm{Y}_{-7}$ to $\mathrm{Y}_{0} ; \mathrm{Y}_{0}$ to $\mathrm{Y}_{+4}$; and $\mathrm{Y}_{-7}$ to $\mathrm{Y}_{+4}$. Independent two-tailed t-tests with Satterthwaite approximation for unequal variance were performed for each year of follow-up to test the difference in mean annual DI between PwMS and the references. The mean differences in annual sums of earnings, SA benefits and DP benefits between PwMS and references were calculated with $95 \%$ CI at three time points: $\mathrm{Y}_{-7} ; \mathrm{Y}_{0}$; and $\mathrm{Y}_{+4}$.

Lastly, we conducted linear regression analyses, using the GEE method to analyse how MS influenced the DI trajectory development over the study period. ${ }^{39}$ The GEE models described the difference in the slopes of the DI trajectories from $\mathrm{Y}_{-7}$ to $\mathrm{Y}_{+4}$ between PwMS and the reference group. The method allowed for the dependent repeated measures of DI by accounting for the clustering of observations at both the individual and group levels that violated independence assumptions. ${ }^{39-41}$ The dependent variable, DI, was analysed as a continuous measure. The DI distribution was slightly right skewed, but GEE is a robust method. ${ }^{40}$ The GEE models were computed with the following specifications: a normal distribution, identity link and autoregressive within-subject correlation. The within-subject correlation structure was selected because of the reasonable assumption that the correlation between an individual's annual DI values diminished over time. The models were adjusted for gender, age, education level and country of birth. An additional age variable was included to account for curvilinearity. All variables were entered simultaneously with an interaction term of MS and year to evaluate whether PwMS had a different DI trajectory than the references. The periods prediagnosis and postdiagnosis were assessed in separate models. The GEE model results were presented as unstandardised beta regression coefficients with $95 \%$ CI, which can be interpreted as values in SEK. The significance level for all analyses was $\alpha=0.05$.

\section{RESULTS}

We observed growth of annual DI experienced by both the PwMS and the reference group over the study period. There were significant differences between PwMS and the reference group in mean annual sums of SA benefits, DP benefits and earnings along the disease trajectory. No differences in either the levels or development of mean annual DI between $\mathrm{Y}_{-7}$ and $\mathrm{Y}_{+4}$ were observed.

Table 1 contains a basic description of the study population and shows that the reference group $(n=7847)$ was representative of the PwMS cohort $(n=785)$ on the distribution of these sociodemographic variables. The MS cohort had a mean age of 41 (95\% CI 40.7 to 42.0$)$ in $\mathrm{Y}_{0}$, and a female-to-male ratio of 2.17 .

In $\mathrm{Y}_{0}$, PwMS had a mean annual DI of 177040 SEK (95\% CI 170170 to 183920) (figure 1). PwMS experienced a mean increase in annual DI over the 12-year study period of 52240 SEK (95\% CI 44740 to 59740 ).

\begin{tabular}{|c|c|c|}
\hline & $\begin{array}{l}\text { MS }^{*} \\
\text { n (\%) }\end{array}$ & $\begin{array}{l}\text { References* } \\
\text { n (\%) }\end{array}$ \\
\hline & 785 (100) & $7847(100)$ \\
\hline \multicolumn{3}{|l|}{ Sex } \\
\hline Women & $537(68.4)$ & $5367(68.4) \dagger$ \\
\hline Men & $248(31.6)$ & $2480(31.6) \dagger$ \\
\hline \multicolumn{3}{|l|}{ Age group (years) } \\
\hline $25-34$ & $213(27.1)$ & $2130(27.1) \dagger$ \\
\hline $35-44$ & $279(35.5)$ & $2790(35.6) \dagger$ \\
\hline $45-54$ & $208(26.5)$ & $2077(26.5) \dagger$ \\
\hline $55-59$ & $85(10.8)$ & $850(10.8) \dagger$ \\
\hline \multicolumn{3}{|c|}{ Education (in years) } \\
\hline$\leq 9$ (elementary) $\ddagger$ & $111(14.1)$ & $1107(14.1) \dagger$ \\
\hline $\begin{array}{l}\text { 10-12 (high } \\
\text { school) }\end{array}$ & $355(45.2)$ & $3550(45.2) \dagger$ \\
\hline $\begin{array}{l}>12 \text { (college or } \\
\text { university) }\end{array}$ & $319(40.6)$ & $3190(40.7) \dagger$ \\
\hline \multicolumn{3}{|l|}{ Country of birth } \\
\hline Sweden & $677(86.2)$ & $6770(86.3) \dagger$ \\
\hline $\begin{array}{l}\text { Nordic countries } \\
\text { (except Sweden) }\end{array}$ & $23(2.9)$ & $230(2.9) \dagger$ \\
\hline $\begin{array}{l}\text { EU25 (except } \\
\text { Nordics) }\end{array}$ & $27(3.4)$ & $270(3.4) \dagger$ \\
\hline $\begin{array}{l}\text { Rest of the } \\
\text { world } \neq\end{array}$ & $58(7.4)$ & $577(7.4) \dagger$ \\
\hline
\end{tabular}

*MS diagnosis first registered in 2009 in nationwide inpatient and specialised outpatient registers. References: matched on variable distribution $(1 \rightarrow 10)$ with no registered MS diagnosis in years before 2010.

†Reference group matched to MS cohort on these variables. fIndividuals with missing variables added to lowest category ( $<0.5 \%$ of both study cohorts).

MS, multiple sclerosis.

This increase in mean annual DI was observed in both the periods before (31 930 SEK; 95\% CI 25770 to 38080 ) and after diagnosis (21 730 SEK; $95 \%$ CI 15820 to 27630 ) by dependent t-tests.

To further investigate the mean annual DI of PwMS, comparison was made to the reference group. Figure 2 suggests there were differences in mean annual DI between PwMS and the reference group, where the reference group consistently had higher annual DI means, from 4years prior to MS diagnosis. This suggested gap widened over time. However, independent t-tests suggested that these differences were statistically non-significant ( $p$ values ranged between 0.15 and 0.96) (not presented).

Table 2 displays the differences in the mean annual sums of the main components of DI (earnings, SA benefits and DP benefits) between PwMS and references in $\mathrm{Y}_{-7}$, $\mathrm{Y}_{0}$ and $\mathrm{Y}_{+4}$. In every year, both SA and DP had a median of zero, indicating that most individuals in both groups did 
220000

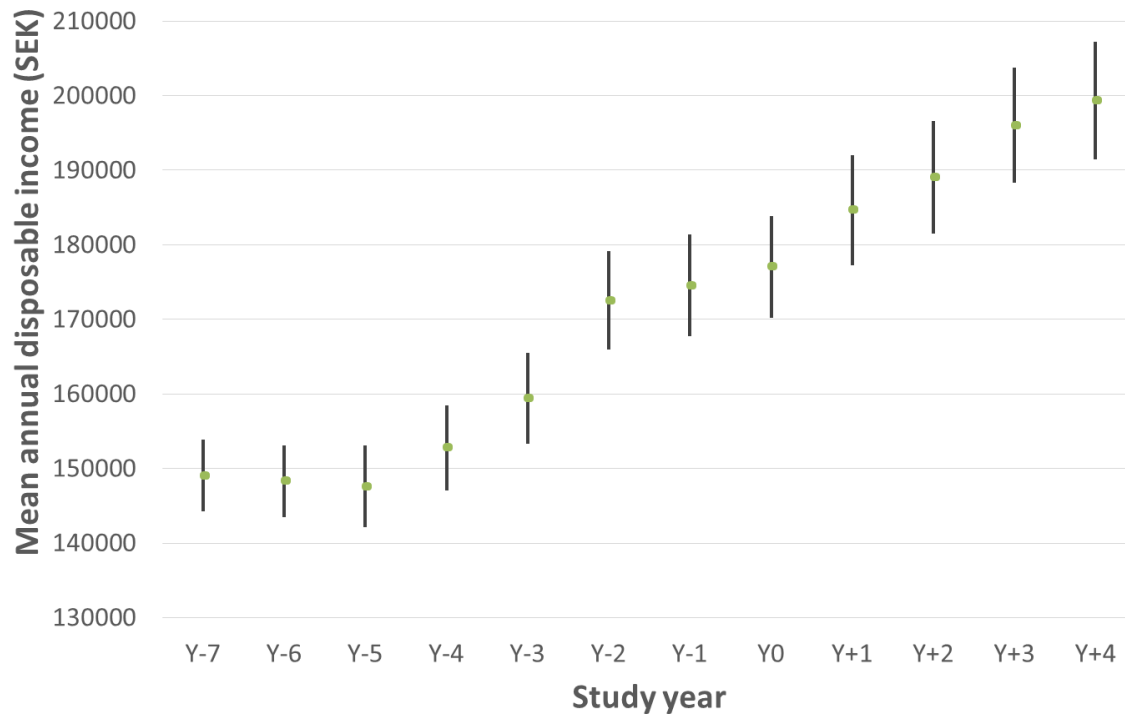

Figure 1 Mean disposable income (DI) $Y_{-7}$ to $Y_{+4}$ among people diagnosed with multiple sclerosis (MS) in $Y_{0}$. Notes: mean annual DI with 95\% Cls illustrated. DI sums are inflated to 2016 values in Swedish Krona (SEK) with the Harmonised Consumer Price Index. In 2017, 100 SEK $\approx 10.5$. MS, individuals with first registered MS diagnosis in $2009\left(Y_{0}\right)$ in national inpatient and specialised outpatient registers.

not receive either benefit (not presented). A trend for PwMS to have greater sums of income from morbidity-related benefits than the references was present from $\mathrm{Y}_{-7}$ (DP mean difference: 5571 SEK; 95\% CI 1773 to 9369). The proportion of PwMS who received each of the benefits, SA and DP, increased over time. However, substantial skewedness of income from these morbidity-related sources remained even among PwMS; in each year less than $30 \%$ of PwMS had annual income from each benefit (except SA in $\mathrm{Y}_{0}, 44 \%$ ). This skewness was larger among the references $(<17 \%)$. Notwithstanding, in every year studied, the mean SA and DP amounts were higher for PwMS than for the reference group with differences in all years, apart from SA benefits in $2002\left(\mathrm{Y}_{-7}\right)$. PwMS had

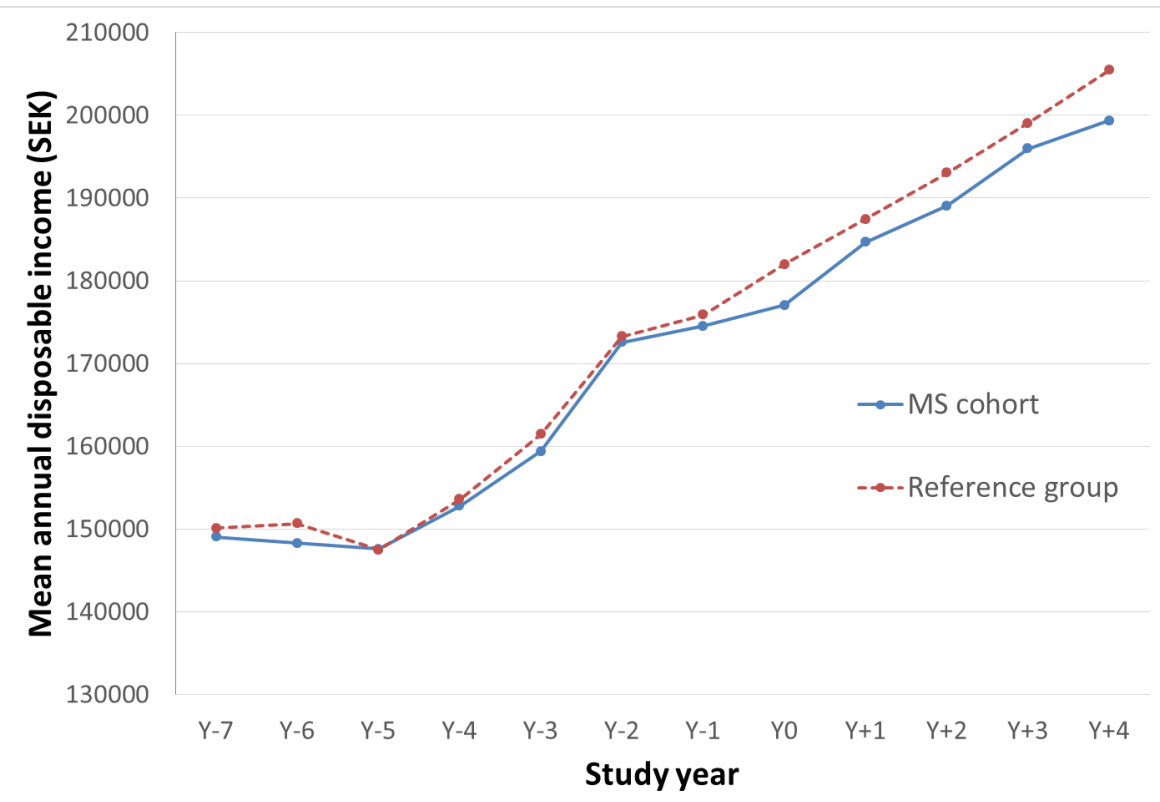

Figure 2 Mean disposable income (DI) $Y_{-7}$ to $Y_{+4}$ among people diagnosed with multiple sclerosis $(M S)$ in $Y_{0}(n=785)$ compared with references $(n=7847)$. Notes: mean annual DI inflated to 2016 values in Swedish Krona (SEK) with Harmonised Consumer Price Index In 2017, 100 SEK $\approx 10.5$. Year of diagnosis $\left(2009=Y_{0}\right)$. MS (solid blue line): individuals with first registered MS diagnosis in $2009\left(Y_{0}\right)$ in national inpatient and specialised outpatient registers. References (dashed red line: matched on four variables $(1 \rightarrow 10)$ with no MS diagnosis registered in years before 2010 in the National Patient Registers. MS, multiple sclerosis. 


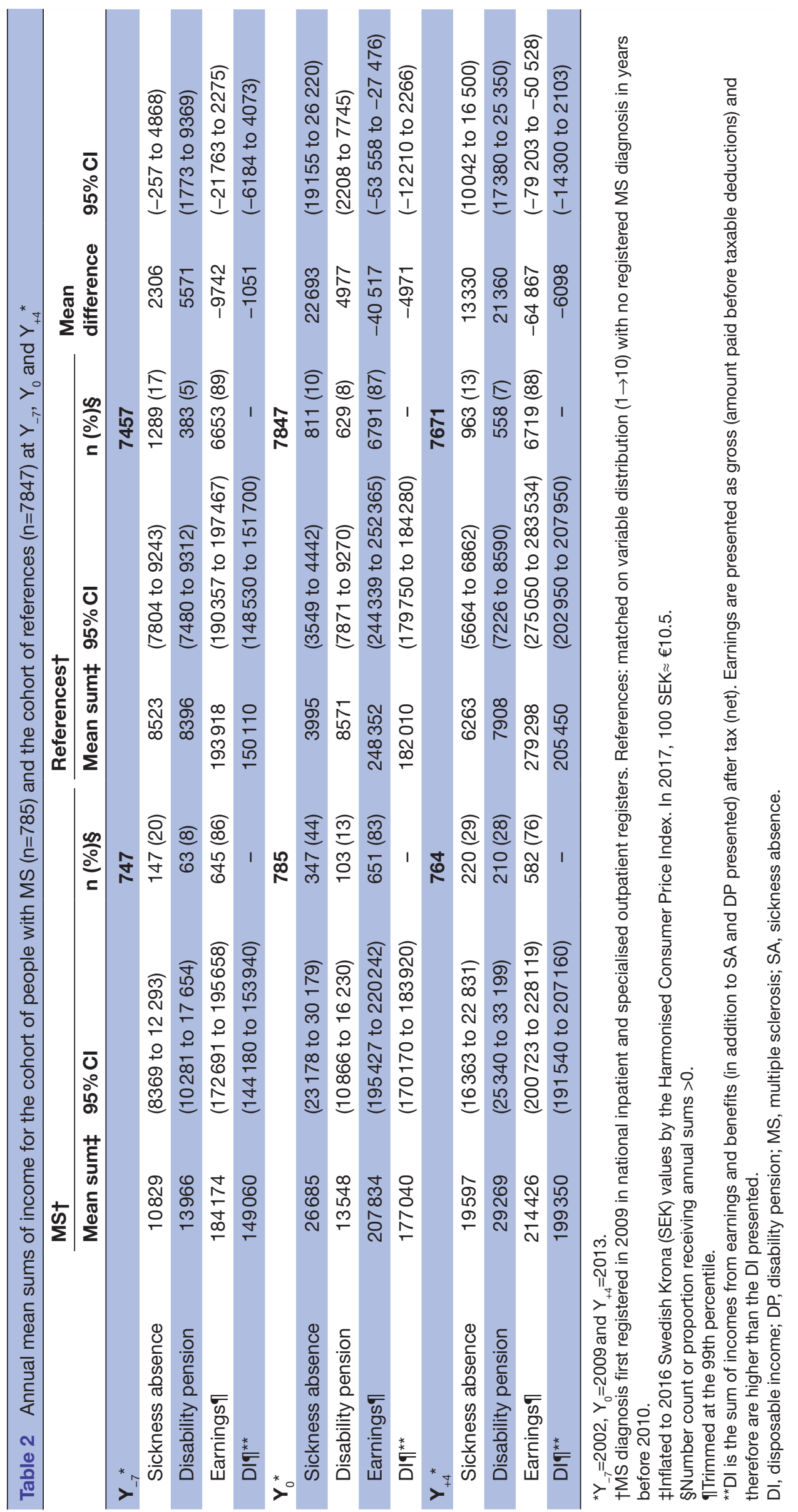


Table 3 Disposable income (DI) trajectory postdiagnosis from $Y_{0}(2009)$ to $Y_{+4}$ (2013) in the cohort of people with MS $(n=785)$ compared with the cohort of references $(n=7847)^{*} \dagger$

\begin{tabular}{lll}
\hline & $\begin{array}{l}\text { Adjusted } \\
\text { regression } \\
\text { coefficient } \$ \S\end{array}$ & $\mathbf{9 5 \%} \mathbf{C l}$ \\
\hline$Y_{+4}(2013)$ & -781 & -6922 to 5360 \\
$Y_{+3}(2012)$ & 1623 & -3839 to 7085 \\
$Y_{+2}(2011)$ & 1200 & -4120 to 6520 \\
$Y_{+1}(2010)$ & 1710 & -3226 to 6646 \\
\hline
\end{tabular}

${ }^{*}$ Reference groups for analysis: $2009\left(Y_{0}\right)$ and reference group. †MS diagnosis first registered in $2009\left(Y_{0}\right)$, in national inpatient and specialised outpatient registers, $n=785$ in 2009. References: matched on variable distribution $(1 \rightarrow 10)$ with no registered MS diagnosis in years before and including 2009, n=7847 in 2009. $\ddagger$ Adjusted for age, gender, education level and country of birth. $\S U n s t a n d a r d i s e d$ beta. Inflated to 2016 Swedish Krona (SEK) values by the Harmonised Consumer Price Index. In 2017, 100 $\mathrm{SEK} \approx € 10.5$.

MS, multiple sclerosis.

a peak in $\mathrm{SA}$ in $\mathrm{Y}_{0}$ with the $\mathrm{DP}$ benefits increasing in the postdiagnosis period, whereas the references had stable DP sums and proportions across follow-up. From the time of diagnosis $\mathrm{Y}_{0}$, PwMS had significantly lower earnings than the reference group, with this trend continuing throughout the postdiagnosis period.

Potential differences in the development of the mean annual DI trajectory of PwMS from that of the matched references were assessed with a GEE model. In figure 2, there were indications of the slopes both diverging prior to diagnosis and realigning to develop more in parallel in the years after diagnosis. All results from the GEE model provided non-significant differences between the development of the DI trajectories of PwMS and the reference group. Table 3 contains the differences in DI development after diagnosis in relation to the year of diagnosis and shows that between $\mathrm{Y}_{0}$ and $\mathrm{Y}_{+4}$ was on an average 781 SEK (95\% CI -6922 to 5360) less for PwMS than for the reference group. Analysis of the prediagnosis period is contained in table 4, where from $\mathrm{Y}_{-7}$ to $\mathrm{Y}_{0}$ the development of mean annual DI for PwMS was on an average 4039 SEK (95\% CI -10536 to 2458) lower than the reference group.

\section{DISCUSSION}

\section{Principal findings}

We have presented the mean DI development for working-aged PwMS from 7 years before to 4 years after diagnosis, in comparison with a population-based stratified matched reference group without MS. Our principal finding was that within the first 4 years after diagnosis, there was little change to PwMS' DI trajectory in comparison with those without MS. Both groups experienced parallel trajectory development despite substantial differences in the individual component sources of income: earnings, SA benefits and DP benefits. Changes
Table 4 Disposable income (DI) trajectory prediagnosis from $Y_{-7}(2002)$ to $Y_{0}(2009)$ in the cohort of people with MS $(n=785)$ compared with the cohort of references $(n=7847)^{\star}+$

\begin{tabular}{lll}
\hline & $\begin{array}{l}\text { Adjusted } \\
\text { regression } \\
\text { coefficient } ¥ \S\end{array}$ & 95\% Cl \\
\hline$Y_{0}(2009)$ & -4039 & -10536 to 2458 \\
$Y_{-1}(2008)$ & 304 & -6135 to 6742 \\
$Y_{-2}(2007)$ & -715 & -6883 to 5454 \\
$Y_{-3}(2006)$ & -2060 & -7588 to 3468 \\
$Y_{-4}(2005)$ & -863 & -6085 to 4358 \\
$Y_{-5}(2004)$ & 258 & -4681 to 5197 \\
$Y_{-6}(2003)$ & -1515 & -4844 to 1813 \\
\hline
\end{tabular}

${ }^{*}$ Reference groups for analysis: $2002\left(Y_{-7}\right)$ and reference group. †MS diagnosis first registered in $2009\left(\mathrm{Y}_{0}\right)$, in national inpatient and specialised outpatient registers $n=785$ in 2009. References: matched on variable distribution $(1 \rightarrow 10)$ with no registered MS diagnosis in years before 2010, n=7847 in 2009.

$\ddagger$ Adjusted for age, gender, education level and country of birth. §Unstandardised beta. Inflated to 2016 Swedish Krona (SEK) values by the Harmonised Consumer Price Index. In 2017, 100 $\mathrm{SEK} \approx € 10.5$.

MS, multiple sclerosis.

in morbidity-related benefits balanced the expected gap from reduced earnings to maintain the economic welfare of PwMS over follow-up. The result that both DI levels and development are similar can be interpreted as responsiveness of the Swedish welfare system to the potential economic consequences of work incapacity through benefit payments in the first years after MS diagnosis.

\section{Interpretation of findings}

Our interpretations are contextualised within the short term, with observation pertaining to the years early in the disease course. This is of importance in the context of a heterogeneous and progressive disease, where baseline disability and age at onset are predictive of progression to milestones of irreversible physical disability. ${ }^{35} 42$

To situate our findings of DI, a Danish study found differences in the levels of mean annual gross income (pretax sums of earnings and benefit payments but excluding SA benefits) only after 20years postdiagnosis, where PwMS received $70 \%$ of the mean annual gross income of matched references. ${ }^{25}$ The difference was attributed to DP benefits (compensated as a proportion of previous earnings) becoming the largest source of income for PwMS by the end of this longer follow-up that allowed for increasing severity of disability and consequent morbidity-related absence from work. ${ }^{25}$ Notable differences exist between the Danish and Swedish social security systems and labour markets. ${ }^{43}$ However, it is likely that PwMS in Sweden would also experience reduced DI after a substantially longer follow-up allowing for further disease progression, as long-term DP benefits compensate lost earnings 
to a lower proportion than short-term SA benefits. ${ }^{10} 25$ Earnings remained the main income source for our MS cohort, where $76 \%$ cohort still participated in paid work to some degree at the end of follow-up, reflecting findings of Wiberg $e t a \hat{l}$ that notwithstanding changes in sources of income around diagnosis, earnings remain the dominant source. Furthermore, Pfleger et $a l^{25}$ concluded that PwMS maintained similar levels of gross income to the references while remaining in paid work. The combination of which supports our findings of similar DI trajectories between PwMS and the references in the short term.

Despite the importance of earnings for maintaining economic welfare of working-aged PwMS, reductions in comparison with references were observed to begin early in the disease course. Similarly to Wiberg et al, we found that PwMS had lower mean annual earnings than the references from diagnosis, with the mean difference increasing with time from diagnosis. ${ }^{3}$ This trend of early and increasing heterogeneity of PwMS' earnings has been postulated to be due to the disparate levels of work incapacity, influenced by severity of physical disability and cognitive function independently, and variations in flexibility of occupations and workplaces to adapt. ${ }^{14} 203044-46$ Furthermore, the level of earnings may be reduced of those who remain economically active due to truncated careers and underemployment. ${ }^{9}$ The accumulation of irreversible physical disability of MS is highly variable and related to both age of clinical onset and current age. ${ }^{42}$ As the disease progresses, future unbalanced changes in the component sources of DI may therefore occur through further reduced earnings due to increasing levels of work incapacity. ${ }^{592547}$

In line with previous research, we identified a larger proportion of PwMS receiving income from morbidity-related benefits than references and PwMS transitioning from SA to DP benefits. ${ }^{3} 1047$ These patterns were not found for the reference group; the proportions of references receiving SA benefits were larger than DP for all years. Nevertheless, most PwMS were observed to not be on either benefit within our study period, further suggesting that early stages of MS morbidity were observed. These morbidity-related benefits have an increasing role in consideration of the progressive nature of MS. ${ }^{10}{ }^{20} \mathrm{SA}$ benefits are designed to compensate periods of temporary absence from work, and following the progressive chronic characteristics of MS, permanent DP can be expected to increase with time. ${ }^{3132147}$ Consistent with the trends we observed, the literature suggests that while SA is highest among PwMS around diagnosis years, DP grants continue to increase with time. ${ }^{1047}$ We observed DP surpassing SA benefits postdiagnosis. This increase of DP benefits can accordingly be expected to continue with time. ${ }^{1022} 47$ Such a continuation would plausibly reduce future DI development due to the lower reimbursement by DP compared with SA benefits. Furthermore, previous research in Sweden, non-specific on diagnosis, suggested an association between SA benefits and lower subsequent DI levels. ${ }^{16}$

\section{Strengths and limitations}

A distinctive characteristic of this explorative study that adds to its strength and external validity was the use of nationwide registers. The registers provided the most complete data available and enabled both the full inclusion of incident cases and use of DI that could capture the complexity of incomes available to PwMS in Sweden including part-time SA and DP grants alongside earnings. Such complex combinations are important to acknowledge, especially with the early focus of our observation period. ${ }^{10}$ Our study reflects common methodological characteristics of register-based income studies of PwMS. MS status was ascertained by formal diagnosis by ICD codes. Despite the possibility for miscoding, this method was more objective than the alternative, onset of symptoms, which suffer inaccuracies from recall bias and attribution to MS. ${ }^{47} 48$ The longitudinal design included both prediagnosis and postdiagnosis periods to observe earlier progressive aspects of MS prior to diagnosis, such as relapses and resultant changes in income sources. ${ }^{4}$

An important limitation of our analyses and interpretations of economic welfare is the short-term perspective. Data were available up to 31 December 2013. The diagnosis year 2009 was selected to balance considerations of follow-up length (both before and after diagnosis) and to have a cohort reflecting current treatments and policy environments, especially regarding stricter requirements for SA and DP grants. ${ }^{33}$ Furthermore, short SA spells ( $<14$ days) were missing, and the SA analyses may therefore be underestimated. However, the DI analyses were unaffected, as short spells were included within the composite indicator under earnings, because such spells are usually employer compensated except for the first uncompensated day. Our analyses assumed homogeneity within PwMS and did not consider the variation within the cohort by either sociodemographic or disease characteristics. We did not differentiate between the different grades of SA or DP benefits, which are a unique feature of the Swedish social insurance system. The cohort being early in the disease course and with high proportions still engaged in paid work, such benefits were likely to be part time for many in the cohort. ${ }^{20} 2230 \mathrm{An}$ additional assumption in our interpretation of economic welfare was that DI was distributed evenly within households according to need, but the actual distribution was unknown. ${ }^{28}{ }^{31}$ Furthermore, informal support by increased earnings of household members was also plausible.

\section{Implications for policy and research}

Our results reflect the combination of a responsive welfare system and the incremental progression of MS morbidity. The finding of unchanged levels and development of economic welfare, as measured by DI, in the presence of MS suggests that the morbidity-related transfer payments buffered the economic consequences of MS of reduced earnings in the years directly after diagnosis. ${ }^{29}$ Our results suggest that society is bearing much of the economic burden associated with MS, which the 
individual would otherwise experience. The observation that the economic situation does not seem to differ much between the groups implies that that the flexible system of morbidity-related benefits that differentiate morbidity situations and levels of work incapacity in allowing parttime grants is necessary for PwMS to maintain similar levels of economic welfare to the general population early in the disease trajectory.

Moreover, current focus of MS treatment is on early intervention to delay disease progression, which should further preserve work capacity for longer periods postdiagnosis. ${ }^{14223548}$ These delaying effects of early initiated treatments have been found to extend to socioeconomic outcomes and reduce the risk of full-time DP which, in light of the lower compensation for DP benefits, could provide further protections of economic welfare. ${ }^{22}$

Future research is required; we did not have the opportunity to capture long-term DI changes that may occur with further disease progression and increasing work incapacity. Lastly, we did not consider PwMS older than 65 years who may experience different DI development to our study cohort as a consequence of different income sources and benefit entitlements. This would be of particular interest in the Swedish context where the prevalent MS population is comparatively older than in other European countries. ${ }^{5}$ Our interpretations for working-aged persons with MS focused on the role of DP benefits, which are not available for older adults.

\section{CONCLUSIONS}

Our results indicate that working-aged PwMS as a group have similar DI growth to those without MS in Sweden around time of diagnosis and suggest that the potential economic impact of MS for the individual may arise later in the disease course. We found significant differences between PwMS and the population-based reference group in the individual income sources over the 12-year follow-up within both the prediagnosis and postdiagnosis periods. However, no differences were found in the levels or development of the composite measure, annual DI, at least within the first 4 years postdiagnosis. In line with its intentions, the welfare system appears to be responsive to the individuals' economic welfare early in the disease course through balancing PwMS' DI, reflected in the reduced annual earnings balanced by increased SA and DP benefits.

Contributors CM, OM MW, KK and PT participated in the design of the study. CM, $\mathrm{OM}$ and $\mathrm{MW}$ performed data management, and $\mathrm{CM}, \mathrm{OM}, \mathrm{MW}$ and PT were involved in the data analyses. All authors contributed to interpretation of results, participated in the writing and reviewing of the drafts and have approved the final version of the manuscript.

Funding This work was supported by Biogen and the Swedish Research Council for Health, Working Life and Welfare (Dnr 2007-1762, 2009-1758). The design of the study, data collection, analyses, interpretations of data, and writing of manuscript was performed without involvement of the funding bodies, however, Biogen was invited to comment on the manuscript.

Competing interests Declare the following interests with respect to the research, authorship and/or publication of this article: CM, PT, EF and MW received financial support from Biogen for the submitted work. KA has received unrestricted research grants from Biogen. OM and KK had no competing interests to declare.

Patient consent Detail has been removed from this case description/these case descriptions to ensure anonymity. The editors and reviewers have seen the detailed information available and are satisfied that the information backs up the case the authors are making.

Ethics approval The project was approved by the Regional Ethical Review Board of Stockholm, Sweden.

Provenance and peer review Not commissioned; externally peer reviewed.

Data sharing statement The data cannot be made publically available. According to the Swedish Ethical Review Act, the Personal Data Act, and the Administrative Procedure Act, data can only be made available, after legal review, for researchers who meet the criteria for access to this type of sensitive and confidential data. Readers may contact professor Kristina Alexanderson (kristina.alexanderson@ki.se) regarding the data.

Open Access This is an Open Access article distributed in accordance with the Creative Commons Attribution Non Commercial (CC BY-NC 4.0) license, which permits others to distribute, remix, adapt, build upon this work non-commercially, and license their derivative works on different terms, provided the original work is properly cited and the use is non-commercial. See: http://creativecommons.org/ licenses/by-nc/4.0/

(c) Article author(s) (or their employer(s) unless otherwise stated in the text of the article) 2018. All rights reserved. No commercial use is permitted unless otherwise expressly granted.

\section{REFERENCES}

1. Fattore G, Lang M, Pugliatti M. The Treatment experience, burden, and unmet needs (TRIBUNE) study - measuring the socioeconomic consequences of multiple sclerosis. Mult Scler 2012;18(Suppl):5-6.

2. Ahlgren $\mathrm{C}$, Odén A, Lycke J. High nationwide incidence of multiple sclerosis in Sweden. PLoS One 2014;9:e108599.

3. Wiberg M, Friberg E, Stenbeck M, et al. Sources and level of income among individuals with multiple sclerosis compared to the general population: a nationwide population-based study. Mult Scler 2015;21:1730-41.

4. Mills EA, Mirza A, Mao-Draayer Y. Emerging approaches for validating and managing multiple sclerosis relapse. Front Neurol 2017;8 116

5. Brundin L, Kobelt G, Berg J, et al. New insights into the burden and costs of multiple sclerosis in Europe: Results for Sweden. Mult Scler 2017;23:179-91.

6. Krause I, Kern S, Horntrich A, et al. Employment status in multiple sclerosis: impact of disease-specific and non-disease-specific factors. Mult Scler 2013;19:1792-9.

7. Kobelt G, Berg J, Lindgren P, et al. Costs and quality of life of patients with multiple sclerosis in Europe. J Neurol Neurosurg Psychiatry 2006;77:918-26.

8. Smith MM, Arnett PA. Factors related to employment status changes in individuals with multiple sclerosis. Mult Scler 2005;11:602-9.

9. Pearson JF, Alla S, Clarke G, et al. Multiple Sclerosis impact on employment and income in New Zealand. Acta Neurol Scand 2017;136:223-32.

10. Gyllensten $\mathrm{H}$, Wiberg M, Alexanderson $\mathrm{K}$, et al. How does work disability of patients with MS develop before and after diagnosis? A nationwide cohort study with a reference group. BMJ Open 2016;6:e012731.

11. Confavreux $\mathrm{C}$, Vukusic $\mathrm{S}$. The clinical course of multiple sclerosis. Handb Clin Neurol 2014;122:343-69.

12. Confavreux $\mathrm{C}$, Vukusic $\mathrm{S}$, Adeleine P. Early clinical predictors and progression of irreversible disability in multiple sclerosis: an amnesic process. Brain 2003;126(Pt 4):770-82.

13. Gyllensten $\mathrm{H}$, Wiberg $\mathrm{M}$, Alexanderson $\mathrm{K}$, et al. Costs of illness of multiple sclerosis in Sweden: a population-based register study of people of working age. Eur J Health Econ 2018;19:1.

14. Kobelt G, Thompson A, Berg J, et al. New insights into the burden and costs of multiple sclerosis in Europe. Mult Scler 2017;23:1123-36.

15. Naci H, Fleurence R, Birt J, et al. Economic burden of multiple sclerosis: a systematic review of the literature. Pharmacoeconomics 2010;28:363-79.

16. Wiberg M, Friberg E, Palmer E, et al. Sickness absence and subsequent disposable income: A population-based cohort study. Scand J Public Health 2015;43:432-40. 
17. Fritzell J, Nermo M, Lundberg O. The impact of income: assessing the relationship between income and health in Sweden. Scand J Public Health 2004;32:6-16.

18. Solar O, Irwin A. A conceptual framework for action on the social determinants of health. Social determinants of health discussion paper 2 (Policy and Practice). Geneva: World Health Organization, 2010.

19. Kavaliunas A, Danylaite Karrenbauer V, Gyllensten $\mathrm{H}$, et al. Cognitive function is a major determinant of income among multiple sclerosis patients in Sweden acting independently from physical disability. Mult Scler 2017;1352458517740212.

20. Kavaliunas A, Wiberg M, Tinghög $P$, et al. Earnings and financial compensation from social security systems correlate strongly with disability for multiple sclerosis patients. PLoS One 2015;10:e0145435.

21. Chruzander $C$, Tinghög $P$, Ytterberg $C$, et al. Longitudinal changes in sickness absence and disability pension, and associations between disability pension and disease-specific and contextual factors and functioning, in people with multiple sclerosis. J Neurol Sci 2016;367:319-25.

22. Landfeldt E, Castelo-Branco A, Svedbom A, et al. The long-term impact of early treatment of multiple sclerosis on the risk of disability pension. J Neurol 2018;265:701-7.

23. Tinghög P, Hillert J, Kjeldgård L, et al. High prevalence of sickness absence and disability pension among multiple sclerosis patients: a nationwide population-based study. Mult Scler 2013;19:1923-30.

24. Glad SB, Nyland $\mathrm{H}$, Aarseth $\mathrm{JH}$, et al. How long can you keep working with benign multiple sclerosis? J Neurol Neurosurg Psychiatry 2011;82:78-82.

25. Pfleger CC, Flachs EM, Koch-Henriksen N. Social consequences of multiple sclerosis (1): early pension and temporary unemployment-a historical prospective cohort study. Mult Scler 2010;16:121-6.

26. Jennum P, Wanscher B, Frederiksen J, et al. The socioeconomic consequences of multiple sclerosis: a controlled national study. Eur Neuropsychopharmacol 2012;22:36-43.

27. Marmot M. The influence of income on health: views of an epidemiologist. Health Aff 2002;21:31-46.

28. Galobardes B, Shaw M, Lawlor DA, et al. Indicators of socioeconomic position (part 1). J Epidemiol Community Health 2006;60:7-12.

29. Smith JP, Bodies $\mathrm{H}$. Healthy bodies and thick wallets: the dual relation between health and economic status. J Econ Perspect 1999;13:145-66.

30. Salter A, Thomas N, Tyry T, et al. Employment and absenteeism in working-age persons with multiple sclerosis. J Med Econ 2017;20:493-502.

31. Galobardes B, Lynch J, Smith GD, Davey Smith G. Measuring socioeconomic position in health research. Br Med Bull 2007;8182:21-37.

32. Thormann A, Sørensen PS, Koch-Henriksen N, et al. Chronic comorbidity in multiple sclerosis is associated with lower incomes and dissolved intimate relationships. Eur J Neurol 2017;24:825-34.
33. Hillert J, Stawiarz L. The Swedish MS registry - clinical support tool and scientific resource. Acta Neurol Scand 2015;132:11-19.

34. Lidwall U. Termination of sickness benefits or transition to disability pension after changes in sickness insurance: a Swedish register study. Disabil Rehabil 2013;35:118-24.

35. Kavaliunas A, Manouchehrinia A, Stawiarz L, et al. Importance of early treatment initiation in the clinical course of multiple sclerosis. Mult Scler 2017;23:1233-40.

36. Statistics Sweden. Bakgrundsfakta 2016:1 Longitudinell integrationsdatabas för Sjukförsäkrings- och Arbetsmarknadsstudier (LISA) 1990-2013 [Background facts 2016:1 Longitudinal integration database for health insurance and labour market studies (LISA)]. Örebro: Statistics Sweden, Population and Welfare Department, 2016.

37. Statistics Sweden. Konsumentprisindex (KPI) [Consumer price index (CPI)]. 2016 http://www.scb.se/hitta-statistik/statistik-efter-amne/ priser-och-konsumtion/konsumentprisindex/konsumentprisindex-kpi/ (accessed 14 Aug 2017).

38. Lumley T, Diehr P, Emerson S, et al. The importance of the normality assumption in large public health data sets. Annu Rev Public Health 2002;23:151-69.

39. LIANG K-YEE, Zeger SL. Longitudinal data analysis using generalized linear models. Biometrika 1986;73:13-22.

40. Rahman S, Mittendorfer-Rutz E, Alexanderson K, et al. Disability pension due to common mental disorders and healthcare use before and after policy changes; a nationwide study. Eur J Public Health 2017;27:90-6.

41. Hanley JA, Negassa A, Edwardes MD, et al. Statistical analysis of correlated data using generalized estimating equations: an orientation. Am J Epidemiol 2003;157:364-75.

42. Confavreux $\mathrm{C}$, Vukusic $\mathrm{S}$. Age at disability milestones in multiple sclerosis. Brain 2006;129(Pt 3):595-605.

43. Mutual Information System on Social Protection (MISSOC). Your social security rights in Denmark: European Union. European Commission. 2013 www.ec.europa.eu/social/BlobServlet?docld= 13746\&langld=en

44. Kavaliunas A, Karrenbauer VD, Gyllensten H, et al. Income and cognitive impairment among multiple sclerosis patients. Multi Scler 2016;22:12-13.

45. Wiberg M, Friberg E, Palmer E, et al. Earnings among multiple sclerosis patients compared to individuals without multiple sclerosis, in total and for different educational levels and types of occupations - a longitudinal-based cohort study. ECTRIMS 2015:7-10.

46. Kavaliunas A, Karrenbauer VD, Tinghog P, et al. Cognitive function predicts work disability among multiple sclerosis patients. Multi Scler 2017;23:479-80.

47. Landfeldt E, Castelo-Branco A, Svedbom A, et al. Sick leave and disability pension before and after diagnosis of multiple sclerosis. Multi Scler 2016;22:1859-66.

48. Gyllensten $\mathrm{H}$, Wiberg $\mathrm{M}$, Alexanderson $\mathrm{K}$, et al. Comparing costs of illness of multiple sclerosis in three different years: A populationbased study. Mult Scler 2018;24 5208. 